\title{
Comparison of nifedipine, prazosin and hydralazine added to treatment of hypertensive patients uncontrolled by thiazide diuretic plus beta-blocker
}

\author{
L.E. Ramsay, L. Parnell and P.C. Waller \\ University Department of Therapeutics, Royal Hallamshire Hospital, Sheffield S10 2JF, UK.
}

\begin{abstract}
Summary: In 93 patients with hypertension uncontrolled by bendrofluazide $5 \mathrm{mg}$ plus atenolol $100 \mathrm{mg}$ daily, the effects of adding nifedipine (up to $60 \mathrm{mg} / \mathrm{day}, n=31$ ), prazosin (up to $20 \mathrm{mg} /$ day, $n=31$ ), or hydralazine (up to $200 \mathrm{mg} /$ day, $n=31$ ) were compared in a 6 month open random parallel group study. The three drugs did not differ significantly as regards antihypertensive effect, withdrawal rate, total number of side effects, or effect on serum biochemical variables. The pattern of side-effects differed. Headache, flushing and oedema were common with nifedipine, tiredness and drowsiness with prazosin, and headache with hydralazine. Nifedipine is an acceptable third-line antihypertensive drug which may have some advantage over hydralazine and prazosin.
\end{abstract}

\section{Introduction}

Thiazide diuretics and beta-blockers have a favourable benefit-risk ratio even in very mild hypertension, ${ }^{1}$ and should still be regarded as the antihypertensive drugs of choice. However they fail to control the blood pressure in $10-30 \%$ of patients, even when used in combination, and in the stepped-care method of treatment a third drug is added. In one large study ${ }^{2}$ hydralazine and prazosin proved superior to methyldopa, minoxidil and labetalol as third-line drugs. Hydralazine caused fewer subjective side effects than prazosin and appeared to be the third-line drug of choice. ${ }^{2}$ However, it failed to normalize the blood pressure in $75 \%$ of those treated, and it has also emerged that the incidence of the lupus syndrome during long-term hydralazine treatment is unacceptably high, even when the daily dose is limited to $200 \mathrm{mg}^{3}$ There is a clear need for third-line drugs which are safer, better tolerated and more effective. The calcium antagonist nifedipine has proved an effective third-line drug in short-term placebo-controlled studies. 4 We have compared nifedipine, prazosin, and hydralazine as third-line drugs in patients with hypertension uncontrolled by bendrofluazide plus atenolol, in a 6 months randomized parallel group trial.

Correspondence: L.E. Ramsay, M.B., Ch.B., F.R.C.P. Accepted: 4 September 1986

\section{Methods}

\section{Patients}

Ninety-three hypertensive patients (42 men, 51 women; mean age 56 years, range $21-69$ ) consented to the study, which was approved by the hospital ethics committee. They had taken bendrofluazide $5 \mathrm{mg}$ plus atenolol $100 \mathrm{mg}$ daily, and no other antihypertensive drug, for at least 4 weeks, and had supine blood pressure $>140 \mathrm{~mm} \mathrm{Hg}$ systolic or $>95 \mathrm{~mm} \mathrm{Hg}$ diastolic at each of three visits during a 4-week run-in period. Compliance was judged satisfactory by tablet counts.

\section{Study design}

At the end of the 4-week run-in period patients were randomized by opening sealed envelopes to one of three parallel groups receiving nifedipine, prazosin or hydralazine, in addition to bendrofluazide plus atenolol which were continued at constant dosage. Randomization was stratified for sex.

\section{Treatments}

The nifedipine, prazosin and hydralazine preparations and dose increments are shown in Table I. Treatments were all prescribed 'open-label', to be taken twice daily at approximately $0800 \mathrm{~h}$ and $1800 \mathrm{~h}$. The first dose of all treatments was taken on retiring at night. The dose 
was increased (Table I) at 2 week intervals until (1) target blood pressure was reached, i.e. supine systolic $<140 \mathrm{~mm} \mathrm{Hg}$ and diastolic $<95 \mathrm{~mm} \mathrm{Hg}$; or (2) side effects precluded a further increase; or (3) the maximum dose was reached (Table I). After target blood pressure or maximum dosage was reached patients were reviewed every 4 weeks until the total duration of treatment was 6 months. Patients with supine diastolic pressure of $110 \mathrm{~mm} \mathrm{Hg}$ or higher despite maximum dosage were withdrawn for safety reasons, but were included in the analysis. After 6 months of treatment 28 patients had blood pressure measured 3 hours ('peak') and 13 hours ('trough') after dosing, to assess the adequacy of twice daily dose regimens.

\section{Measurements}

Blood pressure, pulse rate, body weight and tablet counts were recorded at each visit, and biochemical variables were measured at entry to and exit from the study. Single readings of supine and standing blood pressure were taken after 15 minutes rest by one observer, using a Hawksley random-zero sphygmomanometer on the right arm supported at heart level, and recording phase 5 diastolic pressure. Side effects were elicited by a standard open question posed by a single observer at each visit - 'Have the tablets upset you in any way?' Responses were noted without editing or interpretation. In addition, a self-administered questionnaire ${ }^{6}$ was completed at entry to and exit from the study.

\section{Statistics}

The predicted power was 0.8 to detect differences between drugs of $10 / 5 \mathrm{~mm} \mathrm{Hg}$ at the $5 \%$ significance level. ${ }^{7}$ For analysis of blood pressure, pulse rate and body weight the mean of two run-in measurements, and the two final measurements (5 and 6 months), were used. The three treatments were compared by Kruskal-Wallis one way analysis of variance followed, when they differed significantly, by the Mann-Whitney U-test. ${ }^{8}$

\section{Results}

The three groups were well matched at randomization for sex (by design), age, body weight, blood pressure and renal function (Table II).

Overall outcome is shown in Table III. Twentyseven $(29 \%)$ patients discontinued their trial drug because of side-effects. One patient was withdrawn because of incidental illness and was excluded from analysis. The analyses of blood pressure, pulse rat and body weight relate to the remaining 65 patients

Table I Treatment regimens compared, when added to bendrofluazide $5 \mathrm{mg}$ plus atenolol $100 \mathrm{mg}$ daily. The preparations used were: hydralazine $25,50 \mathrm{mg}$ tablets; prazosin $1,2,5 \mathrm{mg}$ tablets; nifedipine $10 \mathrm{mg}$ capsules

\begin{tabular}{|c|c|c|c|}
\hline Dose increment & Nifedipine & Prazosin & Hydralazine \\
\hline $\begin{array}{l}1 \\
2 \\
3 \\
4 \\
5\end{array}$ & $\begin{array}{l}10 \mathrm{mg} \text { b.d. } \\
20 \mathrm{mg} \text { a.m; } 10 \mathrm{mg} \text { p.m. } \\
20 \mathrm{mg} \text { b.d. } \\
30 \mathrm{mg} \text { a.m; } 20 \mathrm{mg} \text { p.m. } \\
30 \mathrm{mg} \text { b.d. }\end{array}$ & $\begin{array}{l}0.5 \mathrm{mg} \mathrm{b.d} \\
1 \mathrm{mg} \mathrm{b.d.} \\
2 \mathrm{mg} \mathrm{b.d.} \\
5 \mathrm{mg} \text { b.d. } \\
10 \mathrm{mg} \mathrm{b.d.}\end{array}$ & $\begin{array}{l}25 \mathrm{mg} \text { a.m. } \\
25 \mathrm{mg} \text { b.d. } \\
50 \mathrm{mg} \text { b.d. } \\
75 \mathrm{mg} \text { b.d. } \\
100 \mathrm{mg} \mathrm{b.d} .\end{array}$ \\
\hline
\end{tabular}

Table II Comparability of the three treatment groups at randomization. Mean (s.d.) data

\begin{tabular}{lccc}
\hline & Nifedipine & Prazosin & Hvdralazine \\
\hline No. of patients & 31 & 31 & 31 \\
Sex (male : female) & $14: 17$ & $14: 17$ & $14: 17$ \\
Age (years) & $55(12)$ & $58(10)$ & $56(10)$ \\
Weight (kg) & $75(15)$ & $74(15)$ & $73(16)$ \\
Supine systolic $(\mathrm{mm} \mathrm{Hg})$ & $159(11)$ & $161(12)$ & $158(11)$ \\
Supine diastolic $(\mathrm{mm} \mathrm{Hg})$ & $100(8)$ & $101(5)$ & $100(7)$ \\
Standing systolic $(\mathrm{mm} \mathrm{Hg})$ & $148(15)$ & $152(16)$ & $148(13)$ \\
Standing diastolic $(\mathrm{mm} \mathrm{Hg})$ & $94(7)$ & $97(5)$ & $96(7)$ \\
Serum creatinine $(\mu \mathrm{mol} / \mathrm{l})$ & $108(31)$ & $98(17)$ & $103(21)$ \\
\hline
\end{tabular}


Table III Overall outcome of treatment in the 93 patients randomized

\begin{tabular}{lccc}
\hline & Nifedipine & Prazosin & Hydralazine \\
\hline No. of patients randomized & 31 & 31 & 31 \\
Withdrawn because of: & & 7 & 12 \\
$\quad$ side effects & 8 & 0 & 0 \\
diastolic $>109$ mm Hg, maximum dose* & 1 & 1 & 1 \\
$\quad$ default* & 0 & 0 & 18 \\
$\quad$ unrelated illness** & 0 & 22 & 18
\end{tabular}

*Final observations were included in the ' 6 month' analyses of blood pressure, pulse and body weight; **Excluded entirely from analysis.

Table IV Mean (s.d.) changes in blood pressure, pulse rate and body weight after 6 months of treatment (including final data for three patients withdrawn because of poor blood pressure control or default - see Table III)

\begin{tabular}{|c|c|c|c|}
\hline & Nifedipine & Prazosin & Hydralazine \\
\hline $\begin{array}{l}\text { No. of patients } \\
\text { Supine systolic (mm Hg) } \\
\text { Supine diastolic }(\mathrm{mm} \mathrm{Hg}) \\
\text { Standing systolic }(\mathrm{mm} \mathrm{Hg}) \\
\text { Standing diastolic }(\mathrm{mm} \mathrm{Hg}) \\
\text { Supine pulse rate (beats/min) } \\
\text { Standing pulse rate (beats/min) } \\
\text { Body weight (kg) } \\
\text { Final dose (mg/day) }\end{array}$ & $\begin{aligned} & 23 \\
- & 25(13) \\
- & 15(11) \\
- & 30(12) \\
- & 12(11) \\
+ & 1(9) \\
+ & 2(8) \\
0(2.1) & 50.4\end{aligned}$ & $\begin{array}{c}24 \\
-25(18) \\
-13(6) \\
-29(19) \\
-17(7) \\
+2(8) \\
+3(6) \\
+1.4(1.9)^{* *} \\
14.0\end{array}$ & $\begin{array}{l}18 \\
-19(16) \\
-12(9) \\
-18(18)^{*} \\
-13(9) \\
-1(5) \\
-1(4) \\
-0.6(2.1) \\
150.0\end{array}$ \\
\hline
\end{tabular}

${ }^{*} P<0.05$ versus prazosin, $P<0.01$ versus nifedipine; ${ }^{* *} P=0.05$ versus nifedipine, $P<0.005$ versus hydralazine.

The three drugs did not differ significantly as regards changes in supine blood pressure at six months (Table IV). The fall in supine mean arterial pressure (diastolic $+1 / 3$ pulse pressure) with nifedipine was slightly larger than that for hydralazine (by $4.1 \mathrm{~mm} \mathrm{Hg}, 95 \%$ confidence interval [CI] -2.6 to $+10.7 \mathrm{~mm} \mathrm{Hg}$ ), and prazosin (by $1.3 \mathrm{~mm} \mathrm{Hg} 95 \% \mathrm{CI}$ -4.6 to $7.1 \mathrm{~mm} \mathrm{Hg}$ ). Of all those randomized, target blood pressure (supine systolic $<140 \mathrm{~mm} \mathrm{Hg}$ and diastolic $<95 \mathrm{~mm} \mathrm{Hg}$ ) was attained at 6 months in $52 \%$ with nifedipine, $45 \%$ with prazosin and $33 \%$ with hydralazine. Comparing measurements 13 hours after dosing to those 3 hours after dosing, blood pressure tended to rise on all three drugs. Supine mean arterial pressure rose by $7.0 \mathrm{~mm} \mathrm{Hg}$ on nifedipine $(n=11), 3.5 \mathrm{~mm} \mathrm{Hg}$ on prazosin $(n=10)$ and $4.7 \mathrm{~mm} \mathrm{Hg}$ on hydralazine $(n=7)$.

The fall in standing systolic pressure at six months was less with hydralazine than with nifedipine $(P<0.01)$ or prazosin $(P<0.05)$ (Table IV).

Weight increased significantly during prazosin treatment $(+1.4 \mathrm{~kg})$ when compared to nifedipine $(0.0 \mathrm{~kg}, P=0.05)$ or hydralazine $(-0.6 \mathrm{~kg}, P<0.005)$ treatment (Table IV).
Twenty-six per cent of patients stopped nifedipine, $23 \%$ stopped prazosin, and $40 \%$ stopped hydralazine because of side effects (Table V), after an average of 11 weeks treatment (range 1-23 weeks). The drug was stopped by the patient rather than the doctor in threequarters of cases. The three drugs did not differ in the frequency or total number of side effects volunteered in response to a standard open question (Table V). However the pattern of side effects did differ. Headache, flushing and oedema were common with nifedipine; tiredness and drowsiness with prazosin; and headache with hydralazine. The questionnaires added little information, but did confirm that drowsiness was persistent during prazosin treatment. Drowsiness worsened over 6 months in $32 \%$ of patients taking prazosin, $11 \%$ taking hydralazine, and $5 \%$ taking nifedipine. It improved in $9 \%$ of those taking prazosin, none taking hydralazine, and $23 \%$ taking nifedipine.

Biochemical variables (Table VI) did not differ significantly between the drugs. Nifedipine did not lower serum potassium $(+0.15 \mathrm{mmol} / 1,95 \%$ CI -0.11 to +0.40 ) or increase random blood glucose $(-0.14 \mathrm{mmol} / 1,95 \%$ CI -0.59 to +0.31$)$ when 
Table $\mathbf{V}$ Side effects recorded in response to a standard open question

\begin{tabular}{lccc}
\hline & Nifedipine & Prazosin & Hydralazine \\
\hline No. of patients & 31 & 31 & 30 \\
Drug stopped because of side effects* & 8 & 7 & 12 \\
Visits with any side effect & $53 \%$ & $46 \%$ & $46 \%$ \\
No. side effects per visit & 1.01 & 0.87 & 1.03 \\
No. of patients with:** & 19 & 14 & 9 \\
dizziness & 11 & 5 & 16 \\
headache & 3 & 13 & 5 \\
tiredness & 1 & 12 & 5 \\
drowsiness & 10 & 0 & 3 \\
flushing & 9 & 5 & 0 \\
oedema & 6 & 6 & 6 \\
nausea & & & \\
\hline
\end{tabular}

*Mean dose when stopped: nifedipine $42.5 \mathrm{mg}$, prazosin $9.4 \mathrm{mg}$, hydralazine $108.3 \mathrm{mg}$ daily; ${ }^{* *}$ Symptoms volunteered at any visit during the study.

Table VI Mean (and s.d.) changes in serum biochemical values during 6 months of treatment

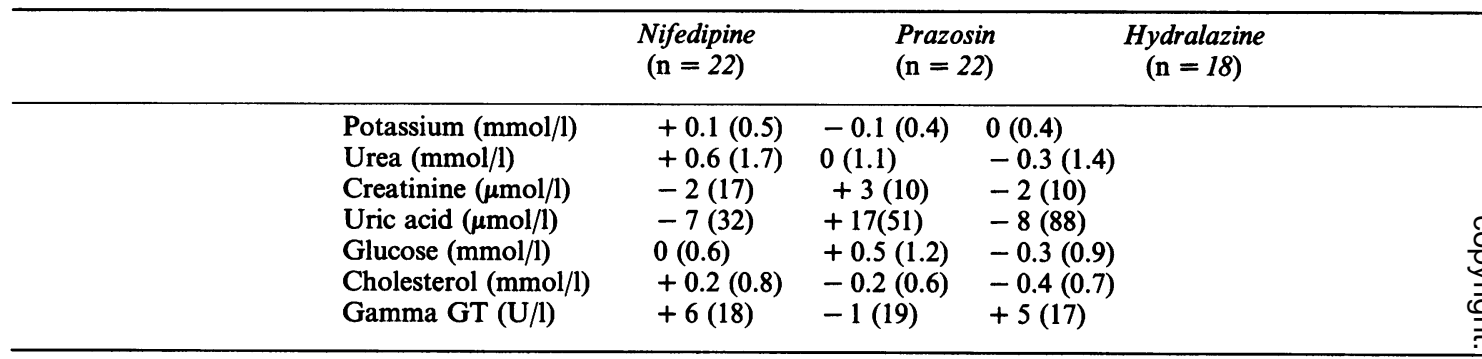

compared to prazosin and hydralazine.

Tablet counts were in error by less than $10 \%$ at $89 \%$ of visits, $10-20 \%$ at $4 \%$ of visits, $>20 \%$ at $0.3 \%$ of visits, and were not returned at $6 \%$ of visits. The accuracy of tablet counts did not differ between the three treatments.

\section{Discussion}

Nifedipine, prazosin and hydralazine are all more effective than placebo as third-line drugs ${ }^{2,4,5}$ and 6 months of placebo treatment could not be justified when designing the present study. In this study design, blood pressure falls by $9 / 5 \mathrm{~mm} \mathrm{Hg}$ supine and $10 / 6$ $\mathrm{mm} \mathrm{Hg}$ standing during 6 months of placebo treatment $^{2}$ and the changes of blood pressure shown in Table IV exaggerate the true drug responses by about this amount. Treatments had to be prescribed 'open label' because of the complexity of the regimens, and this presented particular problems when assessing side effects. To avoid bias we used a standard open question and recorded all responses with no subjective interpretation. The decision whether to continue or stop a drug in a patient with side effects is also open to investigator bias. In this study the patient had stopped or reduced treatment before returning to the clinic in $75 \%$ of instances, and there is unlikely to be any important bias.

The three drugs did not differ significantly as regards their antihypertensive effects, apart from the smaller effect of hydralazine on standing systolic pressure, an observation of doubtful importance. The 95\% confidence intervals indicate that any important difference between the drugs would favour nifedipine, which might lower supine mean arterial pressure more than prazosin or hydralazine by $7 \mathrm{~mm} \mathrm{Hg}$ or $11 \mathrm{~mm} \mathrm{Hg}$ respectively. However this trend in favour of nifedipine would probably be lost towards the end of the dose interval, as the rise in blood pressure 13 hours after dosing was slightly larger for nifedipine than for prazosin or hydralazine. We conclude that there is unlikely to be any important difference between these drugs in antihypertensive efficacy, at least when they are taken twice daily in the doses and formulations we used. 
Subjective side effects were common with all three drugs, and treatment had to be stopped in $29 \%$ of all patients. Treatment was stopped after an average of 11 weeks, an observation which underlines the inadequacy of the ubiquitous 4-6 week trials for assessing the tolerability of antihypertensive drugs. Patients will put up with a great deal when they know that the duration of treatment is limited. The three drugs did not differ significantly as regards withdrawal rate, or the frequency and total number of side effects. The pattern of side effects did differ, and one has to weigh flushing, headache and oedema with nifedipine, tiredness and drowsiness with prazosin, and headache with hydralazine. We believe that drowsiness during prazosin treatment, which was common and persisted during the 6 months of treatment, is the least acceptable of the side effects elicited.

Our findings support the view that the pedal oedema which occurs commonly during nifedipine treatment is not a consequence of generalized fluid retention, as there was a clear dissociation between weight gain and oedema. Nifedipine caused no weight gain, yet caused oedema in $29 \%$ of patients. In contrast, prazosin induced significant weight gain, but caused oedema in only $16 \%$ of patients.

It has been suggested that nifedipine aggravates thiazide-induced hypokalaemia ${ }^{4}$ and may cause glucose intolerance. ${ }^{9}$ Our results do not support these suggestions. The $95 \%$ confidence intervals for changes in serum potassium show that it does not worsen hypokalaemia to any important extent.

Which of these drugs should be preferred as third-

\section{References}

1. Medical Research Council Working Party. MRC Trial of treatment of mild hypertension; principal results. $\mathrm{Br}$ Med $J$ 1985, 291: 97-104.

2. McAreavey, D., Ramsay, L.E., Latham, L. et al. 'Thirddrug' trial: comparative study of antihypertensive agents added to treatment when blood pressure remains uncontrolled by a beta-blocker plus thiazide diuretic. $\mathrm{Br}$ Med $\mathrm{J}$ 1984, 288: 106-111.

3. Cameron, H.A. \& Ramsay, L.E. The lupus syndrome induced by hydralazine: a common complication with low dose treatment. Br Med J 1984, 289: 410-2.

4. Murphy, M.B., Scriven, A.J.I. \& Dollery, C.T. Rôle of nifedipine in treatment of hypertension. Br Med J 1983, 287: 257-259. line treatment? Hydralazine is unsuitable because of the high incidence of the lupus syndrome during more prolonged treatment, ${ }^{3}$ and the choice lies between nifedipine and prazosin. There is little to choose between these two drugs. However the outcome for nifedipine might have been better had we used the slow-release formulation which has become available since this study was initiated. Considering this, and the frequent and persistent drowsiness during prazosin treatment, we now prefer nifedipine.

The whole concept of stepped-care treatment has been called into question recently. The suggestion is that substitution of drugs such as calcium antagonists or ACE inhibitors may be preferable to stepwise addition of drugs. This may be so, and the results of this study and a similar one published previously ${ }^{2}$ certainly highlight the limitations of the third-line drugs currently available. However these limitations were exposed only in large prospective studies of several months duration. Those who advocate substitution rather than stepped-care would be on stronger ground if they could cite similar studies showing that the outcome of such treatment is more satisfactory, or even as satisfactory, as that of stepped-care treatment.

\section{Acknowledgements}

Grants in support of L.P. and P.C.W. from I.C.I. and Janssen Pharmaceutical Ltd., respectively, are gratefully acknowledged.

5. Bayley, S., Dobbs, R.J. \& Robinson, B.F. Nifedipine in the treatment of hypertension: report of a double blind controlled trial. Br J Clin Pharmacol 1982, 14: 509-512.

6. Bulpitt, C.J. \& Dollery, C.T. Side-effects of hypotensive agents evaluated by a self-administered questionnaire. $\mathrm{Br}$ Med J 1973, 3: 485-490.

7. Freestone, S., Silas, J.H. \& Ramsay, L.E. Sample-size for short-term trials of antihypertensive drugs. $\mathrm{Br} \mathrm{J}$ Clin Pharmacol 1982, 14: 265-268.

8. Siegal, S. (1956) Non-parametric Statistics for the Behavioral Sciences McGraw Hill, New York.

9. Zezulka, A., Gill, J.S. \& Beevers, D.G. Diabetogenic effects of nifedipine. $\mathrm{Br}$ Med J 1984, 289: 427-428. 